\title{
Isolasi Selulosa dari Serat Tandan Kosong Kelapa Sawit untuk Nano Filler Komposit Absorpsi Suara: Analisis FTIR
}

\author{
Axel Gian A., Moh. Farid, dan Hosta Ardhyananta \\ Departemen Teknik Material, Fakultas Teknologi Industri, Institut Teknologi Sepuluh Nopember (ITS) \\ e-mail: mofaredo@gmail.com
}

\begin{abstract}
Abstrak-Komposit berpenguat nanofiller merupakan salah satu material yang sedang dikembangkan. Salah satu aplikasinya dapat digunakan sebagai bahan akustik. Penggunaan serat alam sebagai penguat pada komposit mendukung regulasi tentang persyaratan habis pakai produk untuk komponen otomotif dengan mengurangi konsumsi polimer. Indonesia merupakan salah satu negara yang membudidayakan kelapa sawit terbesar di dunia. Kelapa sawit mengandung selulosa yang cukup tinggi sehingga dapat dimanfaatkan sebagai penguat pada komposit polimer. Tujuan dari penelitian ini adalah menganalisis ikatan kimia serat setelah diberi perlakuan kimia. Pengujian yang dilakukan dalam penelitian yaitu FTIR. Pembuatan nanoselulosa dengan menggunakan tiga tahap perlakuan kimia yaitu alkalisasi, bleaching dan hidrolisis asam. Setelah dilakukan tiga tahap perlakuan kimia pada serat tandan kosong kelapa sawit, hasil FTIR menunjukkan tiga daerah serapan utama yaitu $3288.08 \mathrm{~cm}^{-}$ 1, $1636.43 \mathrm{~cm}^{-1}$ dan $1089.92 \mathrm{~cm}^{-1}$ yang menunjukkan ikatan $\mathrm{O}-\mathrm{H}$ stretching, O-H deformasi dan C-C stretching. Daerah serapan yang muncul menunjukkan bahwa telah dihasilkan selulosa dan kandungan lignin menghilang.
\end{abstract}

Kata Kunci-Absorpsi Suara, Isolasi, Selulosa, Spektroskopi, Tandan Kosong Kelapa Sawit.

\section{PENDAHULUAN}

$\mathrm{K}$ EBISINGAN merupakan polusi atau gangguan yang berpengaruh terhadap mental dan kesehatan pengguna jalan khususnya di kota besar. Menurut data dari WHO, sebanyak $40 \%$ populasi di Eropa mengalami kebisingan di jalan raya melebihi $55 \mathrm{~dB}$ pada pagi hari, sebanyak $20 \%$ mengalami kebisingan disiang hari sebesar $65 \mathrm{~dB}$ dan lebih dari 30\% mengalami kebisingan dimalam hari melebihi $55 \mathrm{~dB}$. Suara bising akan menggangu konsentrasi dan meningkatkan tekanan darah. Selain itu dapat menggangu kesehatan dan menurunkan kinerja manusia. Di Indonesia sendiri, terdapat peraturan mengenai batas kebisingan yang diatur dalam Peraturan Menteri Negara Lingkungan Hidup Nomor 07 Tahun 2009 tentang ambang batas kebisingan kendaraan bermotor tipe baru bahwa kendaraan bermotor memiliki ambang batas kebisingan rata-rata $80 \mathrm{~dB}$. Telah banyak dilakukan usaha untuk dapat mereduksi kebisingan yaitu dengan menggunakan bahan-bahan peredam dan penyerap suara sebagai material akustik. Material akustik yang dirancang terbuat dari bahan yang berpori, dimana pori-pori ini akan menyerap bunyi yang lebih besar dibandingkan dengan bahan yang lainnya. Dengan adanya pori ini maka gelombang bunyi akan masuk ke dalam material tersebut dan energi suara yang diserap ini dikonversikan menjadi bentuk energi lainnya, pada umumnya diubah ke energi kalor [1].

Penggunaan material pada industri otomotif dan transportasi mulai menggunakan material yang lebih ringan dan komponen yang dapat didaur ulang untuk meningkatkan energi efesiensi, khususnya menggunakan bahan komposit berpenguat serat alam dengan matriks polimer yang mampu menjadi material biodegradable. Penggunaan kembali serat alam, dipicu oleh adanya regulasi tentang persyaratan habis pakai (end of life) produk komponen otomotif. Serat alam merupakan material yang dapat diperbaharui dan diperoleh dari sumber alam yang memiliki beberapa keunggulan, seperti densitas yang rendah, kekuatan spesifik yang memenuhi syarat, kemampuan penyerapan suara yang baik, abrasivitas yang rendah, harga murah, dan kemampuan biodegradable yang tinggi. Serat alam yang sering digunakan untuk bahan absorpsi suara diantaranya adalah serat rami, serat kapuk, serat bambu yang memiliki koefisien absobrsi yang cukup baik. Di Indonesia salah satu serat alam yang banyak terbuang yaitu kelapa sawit. Sisa dari pengolahan kelapa sawit yaitu $70 \%$ daun palem, $10 \%$ tandan kosong dan 5\% batang. Bagian dari kelapa sawit yang dapat diekstraksi seratnya adalah batang, daun palem dan tandang kosong. Tandan kosong merupakan salah satu bagian yang sangat berpotensi memberikan serat yaitu sebesar 73\% [2].

Telah banyak penelitian mengenai pengaplikasian komposit dengan menggunakan serat alam sebagai material penyerap suara. Komposit polyester berpenguat bambu-rami dengan aspek rasio 90, nilai $\alpha$ serat rami mencapai 0.836 pada frekuensi $125 \mathrm{~Hz}$. Serat bambu mencapai nilai $\alpha 0.972$ pada frekuensi $1000 \mathrm{~Hz}$. Terdapat kenaikan secara signifikan nilai koefisien absorbsi suara pada frekuensi $125 \mathrm{~Hz}$ untuk material poliester berpenguat serat rami dan pada frekwensi menengah $1000 \mathrm{~Hz}$ untuk material poliester berpenguat serat bamboo [3].

Penelitian Farid dan Tri (2013) mengatakan bahwa komposit poliester berpenguat serat ramie pada frekuensi 1255 $\mathrm{Hz}$ memiliki nilai koefisien absorpsi suara $(\alpha)$ sebesar 0.835 [4].

Selulosa dengan formula $\left(\mathrm{C}_{6} \mathrm{H}_{10} \mathrm{O}_{5}\right) \mathrm{n}$ adalah polimer alami dengan rantai panjang yang terbentuk dari molekul-molekul kecil yang saling terhubung. Rantai selulosa mengandung gula, ß-D-glukosa [5]. Gula saling terhubung dengan menghilangkan kandungan air. Penghilangan kadar air dilakukan dengan menggabungkan grup $\mathrm{H}$ dan $-\mathrm{OH}$. Gula yang saling terhubung menghasilkan disakarida yang dikenal sebagai cellobiose [6]. Selulosa merupakan substansi yang tidak larut dalam air yang 
terdapa di dalam dinding sel tanaman terutama dari bagian batang, tangkai dan semua bagian yang mengandung kayu. Selulosa merupakan hompolisakarida yang mempunyai molekul berbentuk linear [7]. Struktur yang linear menyebabkan selulosa bersifat kristalin dan tidak mudah larut. Selulosa tidak mudah didegradasi secara kimia maupun mekanis. Di alam, selulosa berasosiasi dengan polisakarida lain seperti hemiselulosa dan lignin membentuk kerangka utama dinding sel tumbuhan [8].

Lignin $\left(\mathrm{C}_{9} \mathrm{H}_{10} \mathrm{O}_{2}\left(\mathrm{OCH}_{3}\right) \mathrm{n}\right)$ adalah salah satu komponen penyusun tanaman yang bersama dengan selulosa dan bahanbahan serat lainnya membentuk bagian struktural dan sel tumbuhan. Lignin, yang menyusun hingga $10-25 \%$ dari biomassa lignoselulosa, adalah polimer alam yang kedua paling melimpah. Lignin tidak larut dalam air dan stabil di alam dan bertindak sebagai "lem" yang menghubungkan selulosa dan hemiselulosa [9]. Pada batang tanaman, lignin berfungsi sebagai bahan pengikat komponen penyusun lainnya, sehingga suatu pohon bisa berdiri tegak. Kalau dianologikan dengan bangunan, lignin dan serat-serat tanaman itu mirip seperti beton dengan batang-batang besi penguat di dalamnya, yang memegang serat-serat yang berfungsi seperti batang besi, sehingga membentuk struktur yang kuat [10]. Lignin adalah polimer alami yang terdiri dari molekul fenil propane yang terdapat di dalam dinding sel dan di daerah antar sel (atau lamela tengah).

Dalam pembuatan komposit polimer serat alam, interfacial bonding antara serat dan polimer merupakan hal penting yang harus diperhatikan karena serat alam bersifat hidrofilik dan polimer bersifat hidrofobik. Peningkatan kekuatan ikatan diantara kedua bahan dengan memodifikasi secara kimiawi.

Alkalisasi adalah perlakuan kimia untuk memodifikasi permukaan serat alam yang digunakan sebagai penguat dalam komposit. Perlakuan ini bertujuan untuk memecah ikatan hidrogen sehingga meningkatkan kekasaran permukaan. Alkalisasi menghilangkan lignin, hemiselulosa, lilin dan minyak yang mengelilingi permukaan serat. Proses alkalisasi dilakukan dengan merendam serat ke dalam larutan $\mathrm{NaOH}$ dalam waktu yang ditentukan [11].

Proses pengikisan (bleaching) dengan hidrogen peroksida $\left(\mathrm{H}_{2} \mathrm{O}_{2}\right)$ bertujuan untuk menghilangkan lignin dan hemiselulosa. Hidrogen peroksida sebagai agen oksidasi pada proses bleaching menyebabkan serat mengalami perubahan warna. Ion perhidroksil $(\mathrm{OOH})$ dihasilkan dari penguraian hidrogen peroksida ke dalam larutan alkali. Ion ${ }^{-} \mathrm{OOH}$ menyerang grup lignin dan selulosa [12].

Perlakuan hidrolisis asam bertujuan untuk melarutkan bagian amorfus sehingga mereduksi ukuran serat. Ketika asam sulfat berdifusi ke dalam serat terjadi pemisahan ikatan glikosidik sehingga terjadi pemisahan fibril pada selulosa [13].

\section{METODE PENELITIAN}

\section{A. Material}

Material yang digunakan dalam penelitian ini adalah tandan kosong kelapa sawit yang diperoleh dari PT. Intan Sejati Andalan. Kelapa sawit ditanam di Dumai, Riau dengan umur 6 tahun. Bahan kimia yang digunakan untuk mengekstraksi serat yaitu natrium hidroksida $(\mathrm{NaOH})$, hidrogen peroksida $\left(\mathrm{H}_{2} \mathrm{O}_{2}\right)$ dan asam sulfat $\left(\mathrm{H}_{2} \mathrm{SO}_{4}\right)$ yang diperoleh dari PT. BRATACO dan UD. Sumber Ilmiah Persada, Surabaya, Indonesia. Gambar 1 menunjukkan serat tandna kosong kelapa sawit.

\section{B. Preparasi Serat}

Serat tandan kosong kelapa sawit dicacah dan diayak hingga ukuran 112-224 $\mu \mathrm{m}$. Serat dilakukan tiga tahap proses kimia yaitu alkalisasi, bleaching dan hidrolisis asam. Alkalisasi bertujuan untuk menghilangkan lignin dan pengotor yang terdapat pada permukaan serat. Alkalisasi dilakukan dengan cara perendaman dalam $\mathrm{NaOH} 2 \%$ berat pada $70^{\circ} \mathrm{C}$ selama 3 jam menggunakan magnetic stirrer. Tahap kedua yaitu bleaching yang bertujuan untuk menghilangkan lignin sisa alkali. Bleaching dilakukan dengan cara perendaman dalam $\mathrm{NaOH} 4 \%$ berat dan $\mathrm{H}_{2} \mathrm{O}_{2} 7.2 \%$ berat pada $55^{\circ} \mathrm{C}$ selama 2 jam menggunakan magnetic stirrer. Tahap terakhir adalah hidrolisis asam yang bertujuan untuk memecah ikatan hidrogen sehingga ukuran tereduksi dari mikro menjadi nano. Hidrolisis asam dilakukan dengan menggunakan $\mathrm{H} 2 \mathrm{SO} 464 \%$ pada $60^{\circ} \mathrm{C}$ selama 45 menit dengan menggunakan metode water bath.

\section{Alat Pengayak (Sieving Machine)}

Pengayakan serat dilakukan untuk memisahkan serat sesuai ukuran yang dikehendaki. Pengayakan menggunakan mesin Fritsch Analysette 3 Pro. Spesifikasi alat ini yaitu daya yang dibutuhkan sebesar 50 Watt, rentang pengukuran $20 \mu \mathrm{m}-63$ $\mathrm{mm}$ dan rentang amplitudo $0.1-3 \mathrm{~mm}$. Eksperimen yang dilakukan menggunakan ayakan berdiameter 112, 140 dan 224 $\mu \mathrm{m}$ dengan amplitude sebesar 1.5 selama 20 menit.

\section{Fourier Transform Infrared (FTIR)}

Pengujian FTIR dilakukan untuk mengetahui ikatan kimia serat pada setiap tahap perlakuan kimia. Mesin FTIR yang digunakan adalah Nicolet iS10 FT-IR Spectometer, miliki Departemen Teknik Material FTI-ITS, Surabaya. Spesifikasi mesin yaitu dapat dihubungkan dengan komputer menggunakan PC USB 2.0, kebutuhan listrik 100-240 V dan jangkauan spektrum $7800-375 \mathrm{~cm}^{-1}$ dengan menggunakan beam splitter $\mathrm{KBr} / \mathrm{Ge}$.

\section{HASIL DAN PEMBAHASAN}

\section{A. Analisis FTIR}

Serat tandan kosong kelapa sawit memiliki komponen yaitu lignin, hemiselulosa dan selulosa. Ketiga komponen tersebut tersusun atas alkana, ester, aromatik dan alkohol [14]. Hasil spektrum FTIR TKKS (a) tanpa perlakuan, (b) alkalisasi, (c) bleaching dan (d) hidrolisis ditunjukkan pada Gambar 2. 


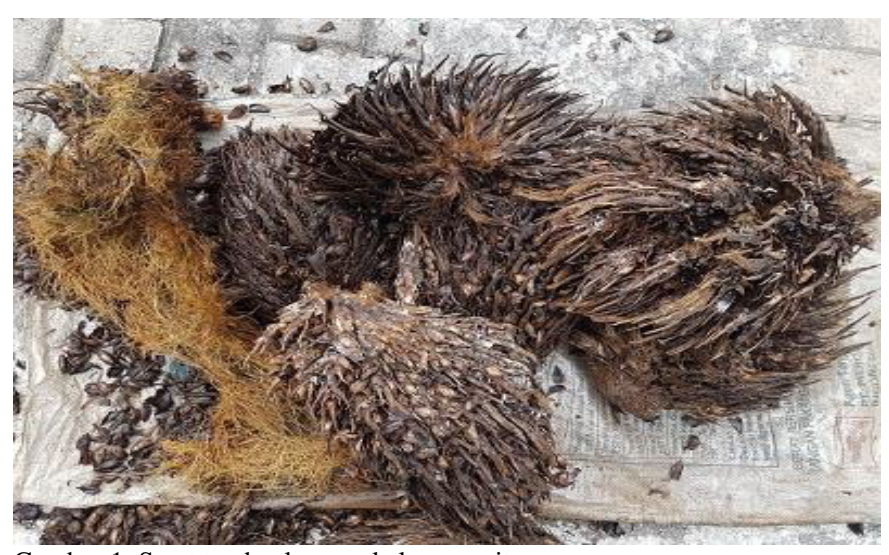

Gambar 1. Serat tandan kosong kelapa sawit.

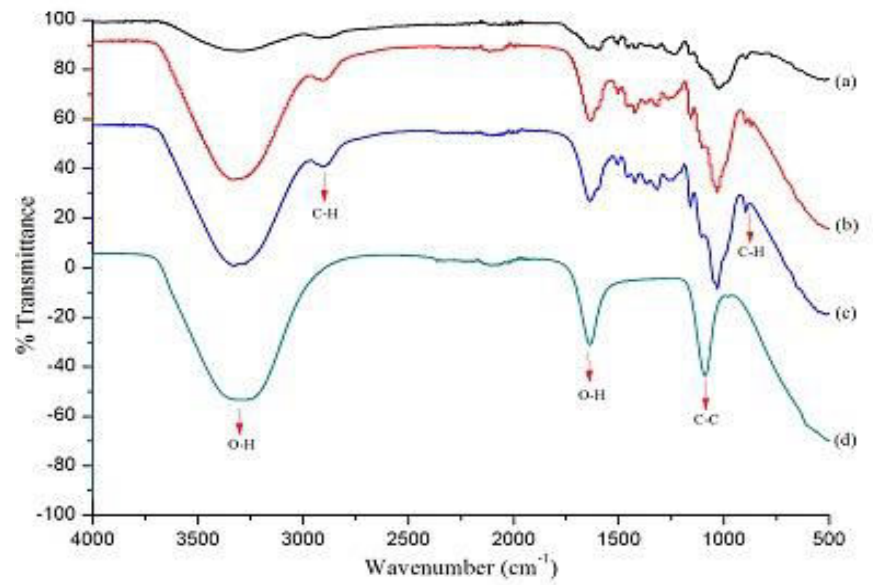

Gambar 2. Spektrum FTIR TKKS (a) tanpa perlakuan, (b) alkalisasi, (c) bleaching dan (d) hidrolisis.

Absorpsi yang kuat dan luas berada pada daerah serapan $3355 \mathrm{~cm}^{-1}$ yang menunjukkan $\mathrm{O}-\mathrm{H}$ peregangan (stretching) pada grup hidroksil selulosa. O-H stretching [15], dari hasil eksperimen ditunjukkan dengan adanya puncak $3289.17 \mathrm{~cm}^{-1}$, $3329.91 \mathrm{~cm}^{-1}, 3327.67 \mathrm{~cm}^{-1}$ dan $3288.08 \mathrm{~cm}^{-1}$ pada semua serat yang diberi perlakuan dan tanpa perlakuan. Daerah serapan pada $2900 \mathrm{~cm}^{-1}$ adalah $\mathrm{C}-\mathrm{H}$ stretching pada $\mathrm{CH}_{2}$ dari grup $\mathrm{CH}_{2}-\mathrm{OH}$ selulosa [16]. Gugus $\mathrm{C}-\mathrm{H}$ alifatik pada pengujian FTIR ditunjukkan dengan adanya puncak 2918.57 $\mathrm{cm}^{-1}, 2910.89 \mathrm{~cm}^{-1}$ dan $2904.75 \mathrm{~cm}^{-1}$ tetapi tidak ditemukan pada serat setelah dihidrolisis.

Lignin ditunjukkan dengan adanya puncak antara 1200 $1300 \mathrm{~cm}^{-1}$ dengan getaran aromatic skeletal [17] pada grafik ditunjukkan dengan adanya puncak $1238.51 \mathrm{~cm}^{-1}$ pada TKKS tanpa perlakuan.

Tabel 1. menunjukkan daerah serapan infra merah serat TKKS tanpa perlakuan, alkalisasi, bleaching dan hidrolisis. Perlakuan alkalisasi mereduksi ikatan hidrogen akibat penghilangan kelompok hidroksil dengan bereaksi bersama sodium hidroksida. Hasil dari proses alkalisasi yaitu meningkatnya konsentrasi - $\mathrm{OH}$, ditunjukkan dengan adanya puncak daerah serapan antara $3300-3500 \mathrm{~cm}^{-1}$ dibandingkan dengan serat tanpa perlakuan. Ikatan $-\mathrm{OH}$ deformasi pada daerah serapan sekitar $1590 \mathrm{~cm}^{-1}$ menunjukkan penyerapan air oleh selulosa [18]. Selain itu, alkalisasi juga menghilangkan daerah serapan $\mathrm{C}=\mathrm{C}$ grup lignin.
Tabel 1.

Daerah serapan infra merah serat TKKS tanpa perlakuan, alkalisasi, bleaching dan hidrolisis

\begin{tabular}{|c|c|c|c|c|}
\hline \multicolumn{4}{|c|}{ Daerah Serapan $\left(\mathrm{cm}^{-1}\right)$} & \multirow{2}{*}{$\begin{array}{c}\text { Ikatan dan } \\
\text { Jenis Gugus } \\
\text { Fungsi }\end{array}$} \\
\hline $\begin{array}{c}\text { Tanpa } \\
\text { perlakuan }\end{array}$ & Alkalisasi & Bleaching & Hidrolisis & \\
\hline 3289.17 & 3329.91 & 3327.67 & 3288.08 & $\begin{array}{c}\text { O-H } \\
\text { peregangan } \\
\text { (stretching) }\end{array}$ \\
\hline 2918.57 & - & - & - & $\begin{array}{c}\mathrm{C}-\mathrm{H} \\
\text { peregangan } \\
\text { (stretching) }\end{array}$ \\
\hline 1593.05 & 1636.99 & 1636.74 & 1636.43 & $\begin{array}{c}\mathrm{O}-\mathrm{H} \\
\text { penekukan } \\
\text { (bending) }\end{array}$ \\
\hline 1505.68 & - & - & - & $\begin{array}{c}\mathrm{C}=\mathrm{C} \\
\text { peregangan } \\
\text { (stretching) } \\
\text { cincin } \\
\text { aromatik }\end{array}$ \\
\hline 1455.69 & - & - & - & $\begin{array}{c}\text { C-H } \\
\text { deformasi }\end{array}$ \\
\hline 1421.92 & 1421.14 & 1424.26 & - & $\begin{array}{c}-\mathrm{CH}_{2} \\
\text { deformasi }\end{array}$ \\
\hline 1238.51 & - & - & - & $\begin{array}{c}\mathrm{C}=\mathrm{C} \text { cincin } \\
\text { aromatik }\end{array}$ \\
\hline- & 1160.2 & 1160.57 & - & $\begin{array}{c}\mathrm{C}-\mathrm{O}-\mathrm{C} \\
\text { peregangan } \\
\text { (stretching) }\end{array}$ \\
\hline 1026.82 & 1032.71 & 1032.75 & 1089.92 & $\begin{array}{c}\text { C-C } \\
\text { peregangan } \\
\text { (stretching) }\end{array}$ \\
\hline 895.80 & - & 896.33 & - & $\begin{array}{c}\text { C-H } \\
\text { deformasi }\end{array}$ \\
\hline
\end{tabular}

Perlakuan kedua adalah bleaching. Bleaching bertujuan untuk menghilangkan kandungan lignin [14] ditunjukkan dengan semakin lanjut tahap proses daerah serapan $\mathrm{C}=\mathrm{C}$ menghilang.

Perlakuan ketiga yaitu hidrolisis asam, tidak menunjukkan ada daerah serapan ikatan $\mathrm{C}=\mathrm{C}, \mathrm{C}-\mathrm{O}-\mathrm{C}$ dan $-\mathrm{CH}_{2}$. Ikatan $\mathrm{C}=\mathrm{C}$ menunjukkan ikatan pada lignin, ikatan $\mathrm{C}-\mathrm{O}-\mathrm{C}$ juga terdapat pada lignin. Daerah serapan sekitar $1420 \mathrm{~cm}^{-1}$ menunjukkan ikatan $-\mathrm{CH}_{2}$ yang berdeformasi dalam selulosa. Daerah ini menunjukkan area kristalin, dimana daerah serapan meningkat seiring proses pemurnian [19]. Setelah dilakukan hidrolisis pada serat TKKS terdapat tiga daerah serapan utama yaitu $3288.08 \mathrm{~cm}^{-1}, \quad 1636.43 \mathrm{~cm}^{-1}$ dan $1089.92 \mathrm{~cm}^{-1}$ yang menunjukkan ikatan $\mathrm{O}-\mathrm{H}$ stretching, O-H deformasi dan $\mathrm{C}-\mathrm{C}$ stretching. Daerah serapan yang muncul menunjukkan bahwa tidak adanya lignin dari perlakuan hidrolisis asam [20]. Perlakuan hidrolisis menunjukkan penurunan \% transmitansi $\mathrm{O}-\mathrm{H}$ disebabkan adanya pemutusan ikatan hidrogen dalam selulosa.

Beberapa gugus fungsi tidak mucul dan bertambahnya konsentrasi $\mathrm{O}-\mathrm{H}$ pada tiap tahap proses perlakuan kimia dikarenakan adanya reaksi. Reaksi-reaksi tersebut dikarenakan penambahan zat-zat kimia seperti $\mathrm{NaOH}, \mathrm{H}_{2} \mathrm{O}_{2}$ dan $\mathrm{H}_{2} \mathrm{OS}_{4}$.

Reaksi yang terjadi pada proses alkalisasi yaitu larutan $\mathrm{NaOH}$ yang terdisosiasi menjadi $\mathrm{Na}^{+}$dan $\mathrm{OH}^{-}$berekasi dengan lignin. Ion $\mathrm{OH}^{-}$bereaksi dengan gugus $\mathrm{H}$ pada lignin yang 
membentuk $\mathrm{H}_{2} \mathrm{O}$. Hal ini menyebabkan gugus $\mathrm{O}$ menjadi radikal bebas dan reaktif dengan $\mathrm{C}$ membentuk C-O-C. Gugus C sudah memiliki empat 'tangan' sehingga serangkaian gugus melepaskan ikatan pada gugus O. Reaksi menghasilkan dua cincin benzene yang terpisah, dimana masing-masing cincin memiliki gugus $\mathrm{O}$ yang reaktif. Gugus $\mathrm{O}$ reaktif ini bereaksi dengan $\mathrm{Na}^{+}$dan ikut larut dalam larutan basa sehingga lignin hilang apabila dibilas. Selain itu, reaksi ini juga menghasilkan $\mathrm{H}_{2} \mathrm{O}$. Selulosa bersifat hidrofilik, maka $\mathrm{H}_{2} \mathrm{O}$ diikat oleh selulosa yang menyebabkan konsentrasi ikatan O-H meningkat.

Proses bleaching bertujuan untuk menghilangkan sisa lignin dari proses alkali dengan memutus ikatan rangkap pada cincin benzene sehingga ikatan $\mathrm{C}=\mathrm{C}$ berkurang, kemudian hilang. Ion $\mathrm{OOH}^{-}$berasal dari reaksi $\mathrm{H}_{2} \mathrm{O}_{2}$ dan $\mathrm{OH}^{-}$dari $\mathrm{NaOH}$ yang terdisosiasi. Ion $\mathrm{OOH}^{-}$bereaksi pada salah satu gugus membentuk gugus $\mathrm{O}$ yang memiliki ikatan rangkap, sehingga ikatan rangkap dalam benzene hilang dan berikatan rangkap dengan $\mathrm{O}$. Hal ini menyebabkan tidak stabilnya gugus benzene. Untuk menstabilkan gugus benzene, ikatan rangkap membentuk ikatan rangkap penstabil dan gugus $\mathrm{O}$ seperti pada cenderung membentuk ikatan rangkap juga untuk menstabilkan gugus dalam benzene dengan memutuskan ikatan dengan gugus yang lain. Pada reaksi ini, ikatan rangkap $\mathrm{C}=\mathrm{C}$ hilang. Gugus radikal $\mathrm{OH} \bullet$ yang terlepas dari ion $\mathrm{OOH}^{-}$yang telah bereaksi kemudian terikat bersama selulosa sehingga membuat konsentrasi ikatan O-H pada selulosa meningkat.

Reaksi hidrolisis asam pada selulosa dengan menggunakan asam sulfat. Asam sulfat yang diencerkan dengan air akan membentuk ion $\mathrm{H}_{3} \mathrm{O}^{+}$yang kemudian ion $\mathrm{H}^{+}$bereaksi dengan salah satu cincin selulosa membentuk ikatan O-H. Reaksi ini menghasilkan $\mathrm{H}_{2} \mathrm{O}$ yang kemudian $\mathrm{H}_{2} \mathrm{O}$ akan bereaksi dengan cincin selulosa yang satunya membentuk ikatan $\mathrm{O}-\mathrm{H}$ dan menghasilkan ion $\mathrm{H}^{+}$. Hasil FTIR menunjukkan kenaikan konsentrasi ikatan $\mathrm{O}-\mathrm{H}$.

\section{KESIMPULAN}

Selulosa didapatkan dengan mengisolasi serat tandan kosong kelapa sawit dengan hidrolisis asam. Hasil FTIR menunjukkan tidak ada daerah serapan selain ikatan kimia selulosa setelah dilakukan tiga tahap perlakuan kimia. Daerah serapan utama setelah proses hidrolisis asama yaitu 3288.08, 1636.43 dan $1089.92 \mathrm{~cm}^{-1}$ yang menunjukkan ikatan $\mathrm{O}-\mathrm{H}$ stretching, O-H deformasi dan C-C stretching.

\section{UCAPAN TERIMA KASIH}

Penulis berterimakasih kepada Program Riset Unggulan Perguruan Tinggi, Kemenristekdikti tahun 2017 atas dukungan dana dalam penelitian ini.

\section{DAFTAR PUSTAKA}

A. Wirajaya, "Karakteristik Komposit Sandwich Serat Alami Sebagai Absorber Suara," Bandung, 2007.

[2] B. Wirjosentono, P. Guritno, and H. Ismail, "Oil palm empty fruit bunch filled polypropylene composites," Int. J. Polym. Mater., vol. 53, pp. 295-306, 2004.
"Correlation between Frequency and Sound Absorption Coeffiecient of Polymer Reinforced Natural Fibre," Adv. Mater. Res., vol. 1112, pp. 329-332, 2015.

[4] M. Farid and T. Heryanto, "Correlation of Normal Incidence Sound Absorption Coefficient (NAC) and Random incidence Sound Absorption Coeffiecient (RAC) of Polyester/Ramie Fibre Composite Materials," Adv. Mater. Res., vol. 789, pp. 269-273, 2013.

[5] Doree, The Methods of Cellulose Chemistry. London: Chapman \& Hall, 1947.

[6] Rahway, The Merck Index. USA: Merck\&Co, 1968.

[7] Lehninger, L. Albert, L. N. David, and M. C. Michael, Lehninger Principles of Biochemistry. New York: Worth Publisher, 2000.

[8] M. T. Holtzapple, "Hemicelluloses," in Encyclopedia of Food Sciences and Nutririon, 2003, pp. 3060-3071.

[9] M. D. Watkins, M. Nuruddin, A. Hosur, and S. Tcherbi-Narteh, "Extraction and characterization of lignin from different biomass resource," J. Mater. Res. Technol., vol. 4, no. 1, pp. 26-32, 2015.

[10] A. Raymond, Young, and Roger M. Rowell, Cellulose Structure Modification and Hydrolysis. New York: Wiley-Interscience, 1986.

[11] X. Li, L. G. Tabil, and S. Panigrahi, "Chemical treatments of natural fiber for use in natural fiber -reinforced composites: A review," J. Polym. Environ., vol. 15, no. 1, pp. 25-33, 2007.

[12] M. Rayung, N. A. Ibrahim, N. Zainuddin, W. Z. Saad, N. I. A. Razak, and B. W. Chieng, "The effect of fiber bleaching treatment on the properties of poly(lactic acid)/oil palm empty fruit bunch fiber composites," Int. J. Mol. Sci., vol. 15, no. 8, pp. 14728$14742,2014$.

[13] X. M. Dong, J. V. Revol, and D. G. Gray, "Effect of Microcrystallite Preparation Conditions on the Formation of Colloid Crystals of Cellulose," Cellulose, vol. 5, pp. 19-32, 1998.

[14] E. Abraham et al., "Extraction of nanocellulose fibrils from lignocellulosic fibres: A novel approach," Carbohydr. Polym., vol. 86, pp. 1468-1475, 2011.

[15] A. H. P. S. Khalil, M. M. Marliana, and T. Alshammari, "Material properties of epoxy-reinforced biocomposites with lignin from empty fruit bunch as curing agent," Bio Resour., vol. 6, pp. 52065223, 2011.

[16] X. Xiao, J. Bian, M. F. Li, H. Xu, B. Xiao, and R. C. Sun, "Enhanced enzymatic hydrolysis of bamboo (dedracolamus gigantus munro) culm by hydrothermal pretreatment," Bioresour. Technol., vol. 159, pp. 41-47, 2014.

[17] N. Reddy and Y. Yang, "Structure and properties of high quality natural cellulose fiber from cornstalks," Polymer (Guildf)., vol. 46, no. 15 , pp. 5494-5500, 2005.

[18] J. Lojewska, P. Miskowiec, T. Lojewski, and L.M. Proniewicz, "Cellulose oxidative and hydrolytic degradation: In situ FTIR approach," Polym. Degrad. Stab., vol. 88, pp. 512-520, 2005.

[19] B. Shanmugarajah, P. L. Kiew, I. M. L. Chew, T. S. Y. Choong, and K. W. Tan, "Isolation of nanocrystalline cellulose (NCC) from palm oil empty fruit bunch (EFB): Preliminary result on FTIR and DLS analysis," Chem. Eng. Trans., vol. 45, pp. 1705-1710, 2015.

[20] M. Ioelovich, "Study of cellulose interaction with concentrated solutions of sulfuric acid," ISRN Chem. Eng., vol. 2012, p. 7, 2012. 